\title{
Integrating R\&D and Marketing in New Product Development
}

\author{
Nuša Fain ${ }^{1,}{ }^{*}$ - Mihael Kline ${ }^{2}$ - Jožef Duhovnik ${ }^{1}$ \\ ${ }^{1}$ University of Ljubljana, Faculty of Mechanical Engineering, LECAD Laboratory, Slovenia \\ 2 University of Ljubljana, Faculty of Social Sciences, Slovenia
}

$R \& D$ - marketing integration is considered to be a critical activity within New Product Development (NPD). A theoretical framework for the study of $R \& D$ - marketing integration levels developed by Gupta et al (1986) is one of the most widely cited $R \& D$ - marketing integration frameworks in scientific literature. It is based on the presumption that strategy, environmental, organizational and individual factors are those determining $R \& D$ - marketing integration levels and consequently NPD success. Several empirical studies have been conducted to test this framework, however most of them have dealt only with portions of Gupta et al (1986)'s model. This paper is an attempt to put forward and test an integrated research protocol for the study of $R \& D$ - marketing integration, based on this theoretical framework. Empirical evidence gained from a questionnaire survey and two company case studies show, that people active within the $R \& D$ - marketing interface perceive the studied constructs as relevant for $R \& D$ - marketing integration, thus giving confirmation to Gupta et al (1986)'s model. The presented research protocol can therefore be considered as a valid start into $R \& D$ - marketing integration research within an integrated framework. (C)2011 Journal of Mechanical Engineering. All rights reserved.

Keywords: marketing, R\&D, integration, NPD, theoretical framework, empirical evidence

\section{INTRODUCTION}

The multifunctional process of new product development (NPD) includes several activities carried out by groups with different abilities, knowledge elements, resources, competences and cultures. A successful NPD process meets market demands and needs with an appropriate technical solution. Marketing supplies the voice of the customer, while research and development (R\&D) uses the company's assets and capabilities to create a product with a differential competitive advantage [1] to [3]. In today's competitive environment, the companies that succeed will be those which develop products that satisfy customer needs better than the products of their competitors. Therefore, it is necessary that companies fully research such needs, and generate ideas and solutions that can best satisfy them. The more innovative the NPD projects are, the greater is the need to integrate marketing and R\&D functions within the company. However, although the need for integration has been widely recognised, the levels of integration of R\&D and marketing in practice have proven to be low.
Marketing researchers see $R \& D$ as a subordinate function and the R\&D handles marketing as a static or even limited function. Integration gaps that hinder the NPD process exist [4].

Gupta et al. [4] have put forward a theoretical framework for the study of R\&D - marketing integration (Fig. 1), based on determining the ideal and needed levels for R\&D marketing integration. This framework is the most widely used and cited framework for the study of R\&D - marketing integration.

The study of literature has shown that ideal levels of integration between $R \& D$ and marketing have been defined ([4] to [6]) and used to analyse companies within different economies. Other authors ([1] and [7]) have defined different integrative mechanisms that should lead to higher levels of R\&D - marketing integration and have tested them within different economies. However, according to our knowledge, none of these studies have dealt with these processes within the same framework. Only parts of [4]'s framework have been tested empirically. Therefore, an integrated empirical study is needed to address the R\&D -

*Corr. Author's Address: University of Ljubljana, Faculty of Mechanical Engineering, 
marketing integration levels. This paper presents such an attempt.

The research presented is twofold. Firstly, the applicability of partial studies of R\&D - marketing integration on different cultural backgrounds is tested as literature study has shown that although the studied research works interpret R\&D - marketing interface within NPD, they do this within leading world economies. This makes the transfer to other economies without regarding national and cultural differences questionable. Therefore, testing the framework is needed for exploring R\&D - marketing integration in NPD context regarding the cultural and national differences among the studied countries. The first objective of this paper is to respond to that need by developing and testing a framework to study the country specific R\&D - marketing integration process within the NPD processes. We do so by studying the R\&D - marketing integration level in Slovenia. Secondly, we put forward a research protocol for the study of R\&D - marketing integration portions of [4]'s model that have been left out of these empirical studies. We test this protocol on two companies within the Slovenian business environment.

The paper is structured into several sections. First, the theoretical framework for our study is presented and put forward the hypotheses. Then, the research methodology is presented. In order to get insight into the R\&D - marketing interface with the focus on culture/nation specific influences, a questionnaire survey within Slovenian SMEs was conducted. In addition, we were interested in how the actors involved within the R\&D - marketing interface experience their NPD processes. In order to gain knowledge on that issue, we have conducted multiple case studies of Slovenian companies with different NPD characteristics. The whole research is set up as an instrumental case study, meaning its aim is to generalise findings and make them applicable to other NPD processes outside the studied companies. The final result of the proposed research strategy is a set of causalities relevant for R\&D - marketing integration. At the end the research findings are compared to the theoretical framework and conclusions are given.

\section{THEORETICAL FRAMEWORK AND HYPOTHESES}

The theoretical framework, presented in Fig. 1, has been presented in the work of [4] and widely used for determining the levels of R\&D marketing integration in different studies (i.e [1], [7] and [8]).

This work obtains its support from strategy-structure-environment paradigms of organisational design, the organisational context of innovation, and the socio-cultural differences between managers and technical specialists, i.e. marketing and R\&D personnel. The rationale for this model is based on three main concepts [4]:

The degree of $R \& D$ - marketing integration required depends on company's new product strategy and its perceived environmental uncertainty.

The company's ability to achieve $R \& D$ - marketing integration is affected by its (1) organisational factors such as structure and reward systems and (2) socio-cultural differences between R\&D and marketing managers.

The integration gap that results from the difference between the perceived need and achieved integration is expected to affect the NPD success of the company.

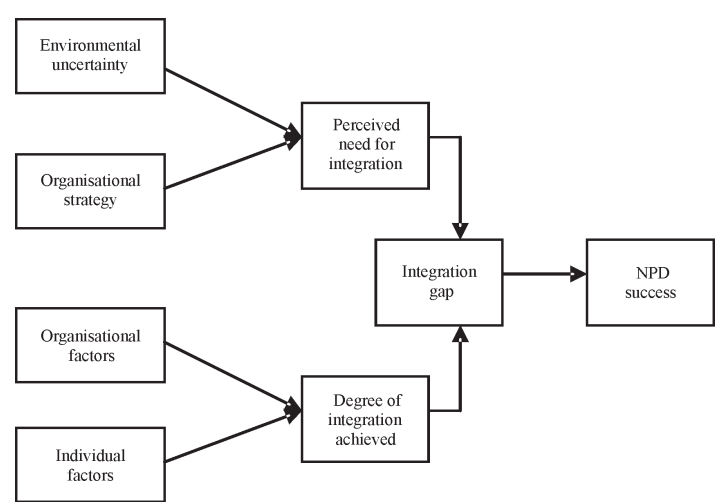

Fig. 1. Theoretical framework for the study of $R \& D$ - marketing interface [4]

Based on the presented framework a research protocol was developed in order to test these concepts. The degree of integration achieved was assessed by conducting a questionnaire survey presented in previous studies ([1] and [7]) within the growing economy of Slovenia. Earlier 
studies of achieved R\&D - marketing integration have been carried out in the Western countries, such as USA, Japan and New Zealand (i.e. [1], [8] and [9]), leaving a gap regarding the R\&D marketing integration in the growing economies. Some comparison of the Western model of achieved R\&D - marketing integration that has been developed from those studies (i.e. [1] and [7]) has been done in reference to China. However, mostly the field of the achieved R\&D - marketing integration in growing economies is still underresearched. Slovenia, as our unit of study, has just recently joined the European Union and is still strongly oriented towards collectivism and has high power distance and uncertainty avoidance levels within its culture [10]. These characteristics put it opposite to many of the Western countries where the orientation is individualist and the levels of power distance and uncertainty avoidance in company culture are low. These characteristics make Slovenia a valid example for study.

The questionnaire used to study the achieved R\&D - marketing integration was adopted from work of [1] and [7], who studied $R \& D$ - marketing integration on Western economies. It covers the areas of integration mechanisms, integration gaps and NPD success and states that the success of NPD depends on the degree of the cross-functional integration gap between R\&D and marketing. Furthermore, the model specifies that the integrative mechanisms (formalisation, centralisation, organisational climate) influence the cross-functional integration gap ([1]; [7]). To minimize the gap, and as such to enhance product success, the integration mechanisms should be influenced. The main hypothesis we derive from literature review of the achieved R\&D - marketing integration is:

H1: Influences on the level of R\&D - marketing integration achieved are culturally determined.

Based on the model we derive a number of sub-hypotheses, first with respect to the relation between the cross-functional integration gap and the integration mechanisms ( $\mathrm{SH} 1$ to $\mathrm{SH} 3$ ) and further regarding the effect of the cross-functional integration gap on NPD success (SH4). The hypotheses are derived from an in-depth literature review of Western R\&D - marketing interfaces.
SH1: A lower degree of formalisation in a company corresponds to a reduced gap between R\&D and marketing.

SH2: A lower level of centralisation in a company corresponds to a reduced gap between R\&D and marketing.

SH3: A higher level of organisational climate used in a company corresponds to a reduced gap between $R \& D$ and marketing.

SH4: A smaller R\&D-marketing gap corresponds with a greater probability of NPD success.

The presumption behind the proposed framework is that if any of the hypotheses supported by the western model do not hold for Slovenian SMEs, then $\mathrm{H} 1$ that the influencing factors are culturally determined, can be confirmed.

The degree of R\&D - marketing integration required, which is, according to [4]'s model dependent on the company's new product strategy and environmental uncertainty has, according to our literature review, not been studied within the same framework; therefore, there is no research protocol to be tested. The second part of our research therefore aims at developing a research protocol that can be used in order to integrate empirical evidence within the same model. We base the proposed protocol on the knowledge presented in the framework of [4] and put forward the second hypothesis:

H2: NPD success is fostered by an optimized level of R\&D - marketing integration.

Since the nature of the research is explorative, we decided to test the hypotheses with an explorative case study, backed up with a survey on a national level. The survey within Slovenian SMEs serves as a pilot study to get an insight into the situation regarding $R \& D$ marketing integration within the studied economy. The following case studiy represents empirical evidence for an integrated [4] R\&D - marketing integration framework.

\section{RESEARCH METHODOLOGY}

We have decided to use two interrelated research strategies to find answers to the presented issues - a questionnaire survey and a case study research. 


\subsection{Questionnaire Survey within Slovenian SMEs}

A questionnaire survey has been developed in order to get an insight into culture specific influences on R\&D - marketing interface within Slovenian SMEs. A survey provides a quantitative or numeric description of trends, attitudes, or opinions of a population, by studying a sample of that population [11]. We chose to study Slovenian SMEs for two main reasons. First, Slovenia is in the process of transition from the technologypush model, which prevailed in the Slovenian central planned economy in the past, towards the opened economy of the Western countries, therefore leaving the field of the R\&D - marketing integration in Slovenian companies open. The second reason for this choice of the unit of analysis is the fact that most of the cited studies about R\&D - marketing integration were conducted on R\&D marketing integration in large companies, leaving the field of small and medium sized enterprises (SMEs) open for further research. SMEs are often cited for being able to react quicker to a changing business environment, having greater internal flexibility, being more willing to take risks, being more efficient, having informal communication coupled with less bureaucracy and having an entrepreneurial spirit [12]. At the same time, the lack of personnel and financial resources for $R \& D$, narrower market niches and the inability to attain economies of scale can limit their NPD success in comparison to larger companies [12]. The differences in the organisational structure and performance therefore exist between the SMEs and large companies that have not been taken into account within the R\&D - marketing integration studies so far. In Slovenia small industry is well developed. More than $93 \%$ of Slovenian companies are classified as small and $4.7 \%$ as medium-sized [13]. Next, proportionally more small manufacturing enterprises with innovation activity are found in Slovenia compared to any other of the European growing economies [14].

We chose to conduct a mailed questionnaire survey for two purposes: (1) our budget for the execution of this part of research was limited, and (2) a mailed questionnaire survey gives the respondent the possibility of answering at their own leisure, therefore it is not as intrusive as other types of surveys. The nature of the survey was cross-sectional, meaning that our intention was to collect data at one point in time. The population we wanted to study was the $R \& D$, marketing and management people within Slovenian SMEs that conducted NPD processes. In a multistage procedure we identified organisations that fitted our criteria, and afterwards obtained names and addresses of individuals from marketing, $R \& D$ and management functions. 197 companies involved in NPD were contacted in order to complete the questionnaire. They were randomly chosen out of SMEs involved in NPD, with the help of statistical programs IPIS and iBON, that group data on Slovenian companies. The data collection was carried out in November 2007 when we sent out the first questionnaires. After two weeks, we did a follow up by sending e-mails and after another two weeks we telephoned the respondents to remind them of the questionnaire. The effective response rate was $26 \%$.

All the items used for measuring the defined constructs in the questionnaire were measured on a 7-point Likert scale and were taken from well-established and validated scales (for details se [1], [7] and [15]).

\subsection{Case Studies within Slovenian Companies}

We were also interested in how the actors involved within the R\&D - marketing interface experience their NPD processes. In order to gain knowledge on that issue, we decided to conduct multiple case studies of Slovenian companies with different NPD characteristics. To find suitable companies we employed some selection criteria, i.e. availability of the company, characteristics of the NPD process. In each company where there is an $R \& D$ function, a marketing function that markets the products developed by $R \& D$ should exist. However, this is not always the case; therefore companies that have distinct $R \& D$ and marketing functions should be determined. Also, the NPD function needs to exist within the company, since our unit of study is the R\&D marketing interface within NPD. After combining these criteria with the availability of the case criteria, two companies were selected. Both of them suite the above criteria and are part of the global business-to-business environment. They 
differ with regard to the products they develop, the way NPD is carried out in the company, the levels of R\&D - marketing integration and the structures of their R\&D and marketing functions.

Case 1 is a company operating in the global market within the fields of development, production, and marketing of commutators. Because their core product has reached the mature phase of its life cycle, the company is extending its product program to electronics, soft ferrites, wound and plastic components.

The company studied in Case 2 develops solutions for steel buildings, roofs, façades, steel constructions, containers, as well as sound and insulation systems. Both of the studied companies work within the high-tech business environment, where innovation, and consequently R\&D play a central role. Both companies have separate R\&D functions that are responsible for innovation within the company. Their marketing sections differ according to their importance within the company, organisation and cooperation with other functions. With this in mind, the two cases satisfy the last two case selection criteria - the ability to learn from the case and the level of variety between cases. Therefore, they represent valid cases for our research.

In order to get an insight into the company profiles, several internal documents of the companies were studied in depth and a literature review of the R\&D - marketing interface was conducted. The questionnaire survey, explained in the previous part of this section, served as a pilot study, enabling us to refine the structure of the interview protocol, which was chosen to be the main data collection tool for the purposes of this section. The use of different data sources and sampling of various types of managers within the companies was employed in order to provide a rich context for investigating the research questions of interest. The structure of the interview was based on the theoretical framework of [2], thus it was divided into four sections. The first set of questions was to determine the strategy the company follows in NPD, therefore we asked the interviewees to elaborate on the company's short-, mid- and long-term goals regarding NPD, about their opportunity search and development, as well as their price politics in product management. The next set of questions was predefined to gain knowledge about the external environment. The questions we asked the interviewees within this part were about the dynamics of the market and competition, their influence on the company's NPD, market trends and company's reaction to all of them. The last influencing factors the organisational structure and individual factors, were partly already represented in the questionnaire survey, but to get a deeper view on the processes within NPD, we also posed several questions about them in the interview. We were interested in the structure of marketing and R\&D departments, their cooperation in NPD projects, the hierarchy within the company and the placement of both departments within the structure, the level of entrepreneurship of the company, the reward/sanctioning system and how informal events within the company are organised.

Prior to conducting the interviews with the chosen managers, the questionnaire survey was sent to all the employees of $R \& D$, marketing and management functions within each company, so that comparisons to the national level results could be made. The interviews were carried out in 2008 and were recorded with the permission of the interviewees.

The first activity of data processing was to make transcripts of the interviews. This led to about 100 pages of text. We sorted these texts into uniform Word documents and changed them to rich text format (.rtf) in order to be able to do open coding within the Scientific Software for content analysis Atlas 5.0. After this formal reorganisation, the units of coding - sentences or paragraphs that captured the ideas of our interviewees completely needed to be determined. The coding was done openly, without a predetermined codebook. The coding was performed by two independent judges on the basis of theoretical knowledge about each of the influencing factors, explained in the model of [4]. A peer-review of the retrieved codes resulted in approximately 300 codes within one case. Merging of synonym codes was performed, irrelevant codes were eliminated and finally the codes were arranged into a hierarchical model, by which the four influencing factors on R\&D marketing integration could be explained. Also, the organisation of R\&D and marketing processes was coded, to gain an insight into how the company operates within NPD. 


\section{RESULTS}

The section is divided into two subsections. Firstly, the results of the national questionnaire survey are presented. Secondly, we present the findings of a questionnaire survey and content analysis for both case studies.

\subsection{Questionnaire Survey Results}

Before testing our sub-hypotheses we analysed the degree to which the three integrative mechanisms (formalisation, centralisation and organisational climate) are independent concepts. The results of the factor analysis and the correlation analysis show that formalisation and organisational climate are to some degree correlated (.395). Despite the result we decided to calculate three separate measures. We calculated their aggregated scores and gained sufficient to good Cronbach alphas (Table 1).

According to our sub-hypothesis lower degrees of formalisation and centralisation will have a positive effect on the level of collaboration between marketing and R\&D. Furthermore, we sub-hypothesised that a higher level of organisational climate has a positive effect on the level of collaboration. Our last sub-hypothesis indicated that the cross-functional integration gap will have a negative effect on the NPD success.

Table 1. Summary statistics for the assessment scales

\begin{tabular}{|l|c|c|c|}
\hline & $\begin{array}{c}\text { Cronbach } \\
\text { Alpha }\end{array}$ & Mean & $\begin{array}{c}\text { Standard } \\
\text { deviation }\end{array}$ \\
\hline Formalisation & .837 & 4.48 & 1.45 \\
\hline Centralisation & .733 & 3.84 & 1.39 \\
\hline $\begin{array}{l}\text { Organisational } \\
\text { climate }\end{array}$ & .674 & 4.83 & .90 \\
\hline $\begin{array}{l}\text { Cross- } \\
\text { functional gap }\end{array}$ & .906 & 1.17 & 1.38 \\
\hline NPD success & .830 & 4.73 & 1.00 \\
\hline
\end{tabular}

Due to the high correlation of the integrative mechanism constructs we decided to test our subhypotheses using Partial Least Squares (PLS) analysis. Rather than assume equal weights for all indicators of a scale, the PLS algorithm allows each indicator to vary in how much it contributes to the composite score of the latent variable. Thus, indicators with weaker relationships to related indicators and the latent construct are given lower weightings. In this sense, PLS is preferable to techniques such as regression which assume error free measurement [16].

We tested the model by employing SmartPLS program [17] and the tested model was significant. The results are depicted in Fig. 2. The model explains .231 (R2) of the variance in NPD success and .235 (R2) of the variance in the Cross-functional gap. The numbers in the figure indicate path coefficients for the variables and their significance.

The effect of formalisation on the level of $R \& D$ - marketing integration was not significant, and our first sub-hypothesis could therefore not be confirmed. However, due to the cultural background of Slovenia, which according to [10] indicates a preference towards the establishment and following of formal rules and procedures, and due to the size of the analysed companies, we decided to also test the direct effect of formalisation on NPD success. The results show there is a moderate positive direct effect present. This positive significant direct effect indicates that NPD success is influenced by formalisation; when the companies are more formalised they report more NPD success.

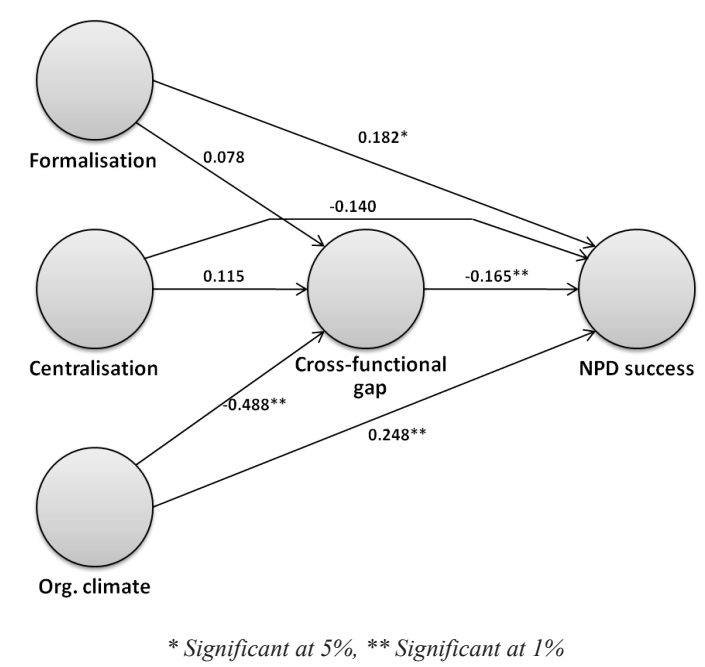

Fig. 2. Summary of path model analysis

Similarly, our second sub-hypothesis cannot be confirmed, as centralisation showed no 
significant effect either on the cross-functional integration gap or the rate of success.

Sub-hypotheses 3 and 4 were supported. The results show that the organisational climate has a negative effect on the cross-functional integration gap, which confirms sub-hypothesis 3. Also, there is a significant negative correlation between the cross-functional integration gap and the rate of NPD success, which supports sub-hypothesis 4. The analysis also revealed that organisational climate has a positive direct effect on NPD success. This positive significant direct effect shows that companies with a better organisational climate are more successful.

\subsection{Case Study Results}

Before the analysis of the interviews, we analysed the answers to the questionnaire survey in order to get some indications of what factors influence the R\&D - marketing integration and what integrative mechanisms influence the crossfunctional gap and NPD success. By comparing the results to the national survey presented in the previous section, we also hope to get some answers to H1, whether the influences on R\&D - marketing integration are culturally bound. The results of the survey are presented jointly for both cases in Table 2 and Fig. 3.

Table 2. Summary statistics for the assessment scales for both cases

\begin{tabular}{|l|c|c|c|}
\hline & $\begin{array}{c}\text { Cronbach } \\
\text { Alpha }\end{array}$ & Mean & $\begin{array}{l}\text { Standard } \\
\text { deviation }\end{array}$ \\
\hline Formalisation & $\mathbf{. 9 4 8}$ & $\mathbf{4 . 8 6}$ & $\mathbf{1 . 7 4}$ \\
& .863 & 4.91 & 1.15 \\
\hline Centralisation & $\mathbf{. 6 2 6}$ & $\mathbf{3 . 7 4}$ & $\mathbf{1 . 4 6}$ \\
& .875 & 3.51 & 1.01 \\
\hline Organisational & $\mathbf{. 8 5 0}$ & $\mathbf{4 . 5 7}$ & $\mathbf{1 . 4 3}$ \\
climate & .800 & 5.09 & 0.81 \\
\hline Cross-functional & $\mathbf{. 9 7 2}$ & $\mathbf{2 . 0 5}$ & $\mathbf{1 . 5 2}$ \\
gap & .932 & 1.23 & 1.19 \\
\hline \multirow{2}{*}{ NPD success } & $\mathbf{. 9 4 7}$ & $\mathbf{4 . 2 0}$ & $\mathbf{1 . 5 5}$ \\
& .923 & 4.78 & .89 \\
\hline \multicolumn{4}{|l}{ Note: Summary statistics for Case I are depicted in Bold, for } \\
\multicolumn{4}{|c}{ Case 2 in Italics }
\end{tabular}

Surprisingly, for Case 1, we could not confirm SH4, as there were no significant effects of the cross-functional gap on NPD success present. We found those effects in Case 2, but were not able to confirm $\mathrm{SH} 3$, as organizational climate had no significant effect on the crossfunctional gap. Both cases therefore give different results as the proposed Western model, thus giving confirmation to our first hypothesis (H1) that $\mathrm{R} \& D$ - marketing integration is culturally bound.

The interview transcripts for both cases were also coded separately and are summarized in Table 3. For each of the four sections studied, examples of answers are shown for both cases, to give insight into the differences.

Findings for Case 1 show that the company follows the analyser strategy, rather than being a prospector in the field. Moreover, the environment in which the company is present is quite stable, as competitors are mostly well known, the customer requirements mostly well specified and the processes guided by legislative restrictions. With regard to the organisational factors, the content analysis confirmed the company is formalised and rather centralised. Several other influencing factors, such as the reward system and the proximity of the functions have been considered by the company and will be implemented within the new $R \& D$ - marketing centre.

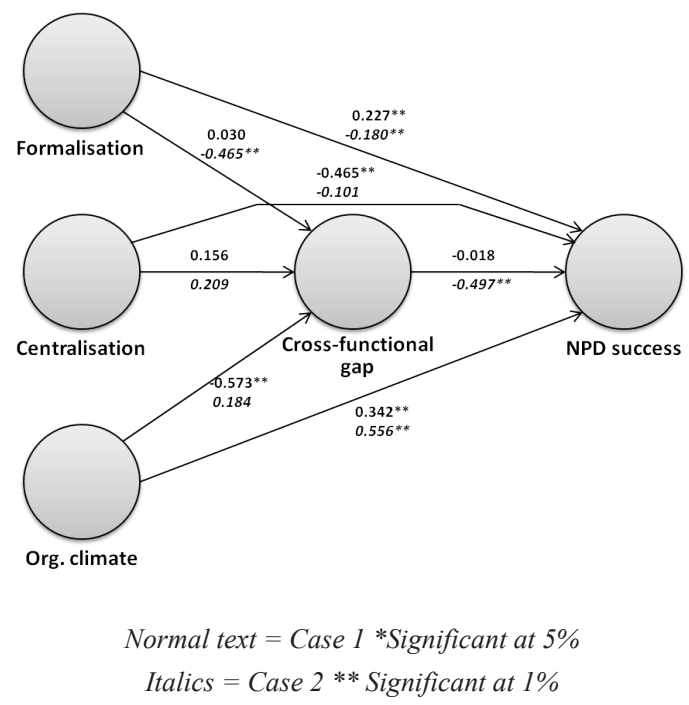

Fig. 3. Summary of the two case path model analyses

The last studied set of influencing factors revealed that the company has an informal procedure of information exchange and yearly 
informal events are the enablers of bonding between different functions.

Next to the influencing factors, the interviewees also explained the function and processes $R \& D$ and marketing do within the company. The main interest for the purposes of this paper was in what phases of the NPD process the two functions cooperate and when their actions are taken separately.

The main effort the two studied functions have to do jointly is maintaining customer relationships. However, there is no general scheme providing a procedure that would define in what phases and how. Marketing is mostly involved in providing an offer to the customer, whereby $R \& D$ is responsible for all the next phases of NPD. Although the company has defined the $R \& D$ - marketing interface as being of strategic importance, no guidelines for the cooperation of functions were given. All cooperation is mostly done on informal levels, which can be confirmed also by the results of the questionnaire survey, where organisational climate is the only factor influencing R\&D - marketing involvement gap.

Table 3. List of example answers to interview questions for both cases

\begin{tabular}{|c|c|c|}
\hline $\begin{array}{c}\text { Studied } \\
\text { dimension }\end{array}$ & Case & Example answers \\
\hline \multirow{2}{*}{ 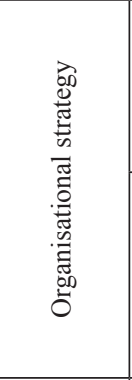 } & 1 & $\begin{array}{l}\text { Marketing: "Our strategic goal is to grow in sales from } 250 \text { to } 350 \text { million by } 2012 \text { and to } 500 \text { million in } 2015 . \\
\text { And for that we'll have to do acquisitions." } \\
\text { Management: "Our wish is that the organic growth is } 5 \% \text {," ... "we have made an ambitious goal to reach } 500 \\
\text { million, which means that the organic growth is just a part of it," ... "the rest is acquisitions." } \\
\text { R\&D: "A wish for diversification exists on the strategic level. There are also other products in sight." }\end{array}$ \\
\hline & 2 & $\begin{array}{l}\text { Management: "The strategy of the company has always been to build a strong network with external partners } \\
\text { and to have R\&D managers that coordinate where the needed knowledge comes from." } \\
\text { Management: "I believe that at the moment we absolutely are the trendsetter." } \\
\text { R\&D: "In the last 6-7 years we are the trendsetter, we set the trends in this field and consequently we control } \\
\text { the dynamics of the market." } \\
\text { Marketing: "We are definitely the leader," ... "we develop most of the products, the most new things." }\end{array}$ \\
\hline \multirow{2}{*}{ 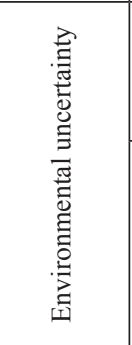 } & 1 & $\begin{array}{l}\text { Marketing: "When you have a mature market the competition is well known. We know everything, what } \\
\text { competences one has, what they know, what they are good at." } \\
\text { R\&D: "Things are well defined, however, you have to reorganise according to what the customers want, } \\
\text { according to the developments within the project." }\end{array}$ \\
\hline & 2 & $\begin{array}{l}\text { Management: "People are much more conservative about new products. If you come to one of your business } \\
\text { partners and say, good news, we have a new product and you'll be the first one we'll build it for, that isn't } \\
\text { necessary good news." } \\
\text { Marketing: "There are very personal relationships built. And when you have a known product, the customer } \\
\text { knows what he is going to get, and the sales person knows what he is selling, there is a trust between them. } \\
\text { With a new product, a problem arises." }\end{array}$ \\
\hline \multirow{2}{*}{ 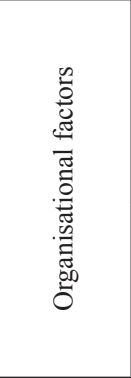 } & 1 & $\begin{array}{l}\text { Marketing: "When you have known products, they are developed according to a certain procedure and this is } \\
\text { much formalised." } \\
\text { R\&D: "All projects run according to certain standards. These standards determine the R\&D process." } \\
\text { Management: "All marketing and R\&D activities will be led from Slovenia." } \\
\text { Marketing: "For strategic projects the decision comes from top management. For small projects the } \\
\text { management of the responsible function can decide." }\end{array}$ \\
\hline & 2 & $\begin{array}{l}\text { Marketing: "The NPD process from idea generation trough the whole process is described. } \\
\text { Management: our top management consists of one member," ... "on a completely strategic level she makes } \\
\text { input into the R\&D process in the sense of general goal definition." } \\
\text { R\&D: "These are some pointers that are checked and then summarized, followed by an explanation," ... "we } \\
\text { also have measurable goals." }\end{array}$ \\
\hline \multirow{2}{*}{ 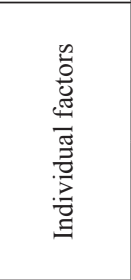 } & 1 & $\begin{array}{l}\text { R\&D: "We have two key information systems, a business and technical information system," ... "however, the } \\
\text { information are not combined." } \\
\text { R\&D: "There is no joint system. Within a certain jurisdiction one can access information on either of the } \\
\text { systems." }\end{array}$ \\
\hline & 2 & $\begin{array}{l}\text { Management: "We are developing an open innovation management system, to enhance and expand cooperation } \\
\text { with external partners." } \\
\text { Management: "People can also cooperate only on projects," ... "this makes the range of possible experts } \\
\text { bigger." }\end{array}$ \\
\hline
\end{tabular}


Findings for Case 2 on the other hand show that the company is a prospector in its own industry. As described by the interviewees, the company is a trendsetter, facing several copying attempts by its competition. In addition, although the industry is conservative, the company is facing a dynamic business environment, where competition is also innovative and offers complete solutions with technical support to the customers. With regard to the organisational factors, the company is formalized in the sense that most of the processes are described in written documents, however, on the other hand, the informal levels of cooperation are also present within the company. The centralisation level is not high. The rewarding system and top management values are well integrated into the company culture. Also, the company has a well developed informal communication structure that goes up to the top management levels. In NPD the company focuses on solving problems for customers by providing complete solutions. Both, R\&D and marketing are part of the NPD process, whereby the focous of marketing is related to building and maintaining relationships with customers and analysing market changes and trends. $\mathrm{R} \& \mathrm{D}$, on the other hand, has to provide the product solution and technical support throughout the process of NPD as well as later on.

As can be seen from the questionnaire survey, the content analysis of the interviews and the company documents, all the processes are formally written down and access to these documents is given to the employees that operate within certain parts of the processes. This type of formalisation enables the company employees to have a good overview of the process, so all the relevant processes can run smoothly. Such notion can also be drawn from the questionnaire survey results, where high levels of formalisation are correlated to a smaller R\&D - marketing gap. Since the processes are well defined, all functions have a clear knowledge on their tasks, so the cooperation can run smoothly. When looking at the greater picture of NPD success, however, two influencing factors need to be considered good organisational climate and lower levels of formalisation. The analysis has shown that both have an influence on NPD success. If higher levels of formalisation enable the processes to run smoothly, lower levels of formalisation and good organisational climate reinforce informal communication and cooperation of the functions, leading to even higher levels of NPD success.

\section{DISCUSSION AND CONCLUSIONS}

Research has shown that there are several factors influencing the R\&D - marketing integration within NPD processes. By conducting a questionnaire survey on a national level within Slovenia we intended to show that there is a cultural effect present within R\&D - marketing integration. Our focus on the R\&D - marketing integration in Slovenia tested the validity of the so called Western model in another cultural and economical arena. We were able to partly confirm the application of the model to other non-western environments; however several interesting limitations with regard to the culture also arose in the analysis.

As formalisation has received mixed support in the previous studies, the lack of support for our first hypothesis was not very surprising. The lack of correlation between the level of formalisation and the size of the cross-functional integration gap might be due to the cultural background of the studied economy. Slovenia scored very high on the dimension of uncertainty avoidance in Hofstede's [10] study of cultural differences between countries. Uncertainty avoidance refers to the preference towards structured processes opposite unstructured processes. High scores on uncertainty avoidance indicate a preference towards the establishment and following formal rules and procedures. In such cultural background, the top managers are involved in operations, precision and punctuality come naturally, flexible working hours are popular and expertise and specialists are highly valued [10]. These characteristics are consistent with a high mean score on the formalisation level of Slovenian SMEs in our study.

Centralisation was also found to be a controversial integration mechanism in previous studies on R\&D - marketing integration. Some studies confirmed its positive effect on R\&D marketing integration, others a negative effect. Our results showed that centralisation has no significant effect on the R\&D - marketing 
integration or NPD success. Reasons for this might be found both in the fact that we studied a growing economy, as well as in the fact that the studied companies were SMEs. Slovenia also scored high on the power distance dimension in Hofstedes' (2001) study. The power distance index measures the extent to which the less powerful members of organisations and institutions accept and expect that power is distributed unequally. A high level of power distance indicates that the members of an organisation expect and accept a high level of authority and centralisation as a predetermined condition, meaning it does not affect their work significantly. The size of the company and relations between the employees may also be the reasons for the lack of support for the proposed hypothesis. For example, the centralisation level might differ if the studied company is a family company or if it employs very few employees. Centralisation effects might be lower in the first example and more obvious in the second. Previous studies also showed that centralisation is usually not present in SMEs, because communication between employees is more direct and the actions of employees more immediate. The mean score for centralisation $(=3.84)$ in our research supports this notion. The lack of centralised relations in the studied companies could therefore be the reason for our results.

Organisational climate has on the other hand proven to be an important factor, effecting the R\&D - marketing integration, as well as the level of NPD success. These results put Slovenia in line with the proposed Western model of R\&D - marketing integration, where a positive effect of organisational climate on R\&D - marketing integration has been proven in several studies. In our study the effect of organisational climate has proven to be the most important integrative mechanism for SMEs, as it had a significant effect on the cross-functional gap and also directly on NPD success.

On the whole, the integration mechanisms considered in our study have proven to be moderately effective for achieving collaboration between the two functions we focused on. However, the theoretical model that we derived from the existing literature did not fit our data. Our results show that the relevance of two of the main construct in the model should be questioned for the situation of SMEs in growing economies. If our arguments hold, the theoretical model would need to be redifined and less emphasis should be put on formalisation and centralisation and much more on organisational climate. It would also be interesting to study different industrial branches and their influence on the studied elements. Although our questionnaire included the definition of the industrial branch of the studied companies, the sample gained is too small to proceed with further study along these lines, so a greater amount of survey response is needed. We will proceed with this in our future research.

The aim of this paper was also to develop a research protocol for an integrated study of $R \& D$ - marketing integration according to Gupta et al [4] framework. Empirical evidence gained from the two case studies show that people active within the R\&D - marketing interface perceive the studied constructs as relevant for R\&D marketing integration, thus giving confirmation to Gupta et al [4] model. The presented research protocol can therefore be considered as a valid start into R\&D - marketing integration research within an integrated framework, however it needs further empirical tests.

With studying two companies within Slovenia, we also wanted to confirm that NPD success is influenced by the level of R\&D marketing integration. The two companies that were studied differ with regard to their strategy, environmental influences, organisational structure and also individual factors that influence NPD. When comparing the perceived integration gap of the two companies, the company of Case 2 seems to have a higher level of R\&D - marketing integration, as the score for perceived crossfunctional integration gap is closer to 0 than it is for Case 1. When comparing this result to the influencing factors, it seems to be consistent with the propositions made by Gupta et al [2] that claim that a prospector strategy, within a dynamic environment call for a greater need for integration. Since the company is successful in NPD as it can hold the position of a trendsetter within the target markets, we can conclude that strategy and environmental uncertainty are influencing factors that can foster or hinder R\&D - marketing integration. On the other hand, the organisational and individual factors have brought 
some contradicting results, compared to Gupta et al [4] and the proposed Western model of $R \& D$ - marketing cooperation. We find an explanation to this within the cultural aspects of NPD. These aspects will also be further studied in the future.

\section{REFERENCES}

[1] Song, M., Thieme, R.J. (2006). A crossnational investigation of the R\&D - marketing interface in the product innovation process. Industrial Marketing Management, vol. 35, p. 308-322.

[2] Fain, N., Moes, N., Duhovnik, J. (2010). The role of the user and the society in new product development. Strojniški vestnik - Journal of Mechanical Engineering, vol. 56, no. 7-8, p. 521-530.

[3] Zargi, U., Kusar, J., Berlec, T., Starbek, M. (2009). A company's readiness for concurrent product and process development. Strojnišski vestnik - Journal of Mechanical Engineering, vol. 55, no. 7-8, p. 427-473.

[4] Gupta, A.K., Raj, S.P., Wilemon, D. (1986). A Model for studying R\&D - marketing interface in the product innovation process. Journal of Marketing, vol. 50, p. 7-17.

[5] Gupta, A.K., Wilemon, D. (1991). Improving R\&D - marketing relations in technologybased companies: Marketing's perspective. Journal of Marketing Management, vol. 7, p. 25-43.

[6] Griffin, A., Hauser, J.R. (1996). Integrating R\&D and marketing: A review and analysis of the literature. Journal of Product Innovation Management, vol. 13, p. 191-215.

[7] Lu, I., Chang, T. (2002). A contingency model for studying $\mathrm{R} \& \mathrm{D}$ - marketing integration in NPD. International Journal of Technology Management, vol. 24, no. 2-3, p. 143-164.

[8] Parry, M.E., Song, M.X. (1993). Determinants of R\&D - marketing integration in high-tech Japanese firms. Journal of Product Innovation Management, vol. 10, no. 1, p. 4-22.

[9] Garett, T.C., Buisson, D.H., Yap, C.M. (2006). National culture and R\&D and marketing integration mechanisms in new product development: A cross-cultural study between Singapore and New Zealand. Industrial Marketing Management, vol. 35, p. 293-307.

[10] Hofstede, G. (2001). Culture's Consequences: Comparing Values, Behaviors, Institutions, and Organisations across Nations. 2nd Ed. Thousand Oaks, London, New Delhi: Sage Publications.

[11] Kleinsmann, M.S. (2006). Understanding Collaborative Design. PhD Thesis, Delft University of Technology, Faculty of Industrial Design Engineering, Delft.

[12] Bommer, M., Jalajas, D.S. (2004). Innovation sources of large and small technology-based firms. IEEE Transactions on Engineering Management, vol. 51, no. 1, p. 13-18.

[13] Sanyal, R.N., Guvenli, T. (2004). Perception of managerial characteristics and organisational performance: comparative evidence from Israel, Slovenia, and the USA. Cross Cultural Management, vol. 11, no. 2, p. 35-57.

[14] Eurostat (2003). SMEs in Europe - Candidate Countries. Office for Official Publications of the European Communities, Luxemburg. Available at: http://epp.eurostat.ec.europa.eu/ cache/ITY_OFFPUB/KS-CJ-04-001/EN/KSCJ-04-001-EN.PDF, accesed on 2008-09-05

[15] Fain, N. (2010). Integrating marketing and $R \& D$ during New Product Development, $\mathrm{PhD}$ thesis, University of Ljubljana, Faculty of Mechanical Engineering, Ljubljana.

[16]Chin, W.W., Marcolin, B.L., Newsted P.R. (1996). A partial least square latent variable modeling approach for measuring interaction effects: Results from a monte carlo simulation study and voice mail emotion/ adoption study. Proceedings of the 17th International Conference on Information Systems, , Cleveland, Ohio, from http://disc-nt.cba. uh.edu/chin/icis96.pdf, accesed on 2008-0322, p. 21-41.

[17]Ringle, C., Wende, S., Will, A. (2005). SmartPLS Version 2.0 M3 from $w w w$. smartpls.de, accesed on 2007-05-14. 